\title{
Antidepressants Self-Poisoning in Suicide and Suicide Attempt: Acute Toxicity and Treatment
}

\author{
Sara Santos Bernardes ${ }^{1}$, Danielle Ruiz Miyazawa ${ }^{1}$, \\ Rodrigo Felipe Gongora e Silva1, Danielle Camelo Cardoso', \\ Estefânia Gastaldello Moreira ${ }^{2}$ and Conceição Aparecida Turini ${ }^{1}$ \\ ${ }^{1}$ Poison Information Centre, University Hospital, State University of Londrina (UEL) \\ ${ }^{2}$ Department of Physiological Sciences, State University of Londrina (UEL) \\ Brazil
}

\section{Introduction}

It is estimated that a quarter of the patients that have been diagnosed with major depression attempt suicide during their lifetime, and $15 \%$ of these patients ultimately die from suicide. Antidepressants have been shown to be a highly effective treatment for depression; paradoxically, to achieve compliance, physicians must give patients access to a toxic drug, and a possible suicide method (Gunnell \& Frankel, 1994; White, Litovitz \& Clancy, 2008; Wong et al., 2010).

Suicide is a serious global public health problem. Nearly 1 million individuals commit suicide every year. The magnitude of the problem is even more significant when the number of attempted but uncompleted suicides - 20 times more common - is included (World Health Organization [WHO], 2010).

Suicide, the act of intentionally killing oneself, ranks among the top 10 causes of death in every country, and is one of the three leading causes of death in 15 to 35-year olds. The number of suicides has increased by 60\% between 1955 and 1995, mainly in men (Gunnell \& Frankel, 1994; Guo \& Harstall, 2004). Risk factors for suicide include psychiatric disorders (depression, personality disorder, alcohol dependence, or schizophrenia), and some physical illnesses.

World Health Organization (WHO) defines suicide attempt or "parasuicide" as an act with a nonfatal outcome, in which an individual deliberately initiates a non-habitual behavior, that without intervention from others will cause self-harm; or deliberately ingests a substance in excess of the prescribed therapeutic dosage, and which is aimed at realizing changes which the subject desired via the actual or expected physical consequences (Guo \& Harstall,2004). Young women with a previous episode are at high-risk of another suicide attempt (Kessler,Borges \& Walters, 1999; Welch, 2001).

Studies on suicide indicated that suicidal behavior and, in particular, the preferred suicide method varies among countries, gender, and age (Ajdacic-Gross et al., 2008; Towsend et al., 2001). European data showed that suicide by poisoning (mainly poisoning by drugs) is the 
most common method among women and firearm suicide among men (Ajdacic-Gross et al., 2008). Assuming there is functional equivalence, we are drawn to the conclusion that unplanned or impulsive suicide in European women is mainly achieved by poisoning using drugs. Other suicide methods that are common in Western countries are hanging and jumping from high places. In Asia, there are other commonly used suicide methods, e.g., poisoning by pesticides, or carbon monoxide poisoning through charcoal burning in confined spaces (Gunnell \& Eddleston, 2003; WHO, 2010).

Access to suicide methods, especially those of easy access, such as large amounts of drugs and alcohol, facilitates impulsive attempts. This is usually observed in younger adults and women (Baca-Garcia et al. 2005; Gunnell \& Frankel, 1994; Wyder \& De Leo, 2007).

In general, men with non-affective psychosis have higher risk of suicide, and are more likely to succeed. Conversely, women with an anxiety disorder, poor social contact, and high risk factor exposure are less likely to die by suicide (Beaustrais, 2001). In a recent study, at a tertiary hospital in Korea, Oh and colleagues (2011) observed that women in their twenties, who live without their family, and have a history of psychiatric treatment and antidepressant use, may reattempt suicide by self-poisoning. Most commonly used methods of fatal and non-fatal suicide can be observed in figure 1.

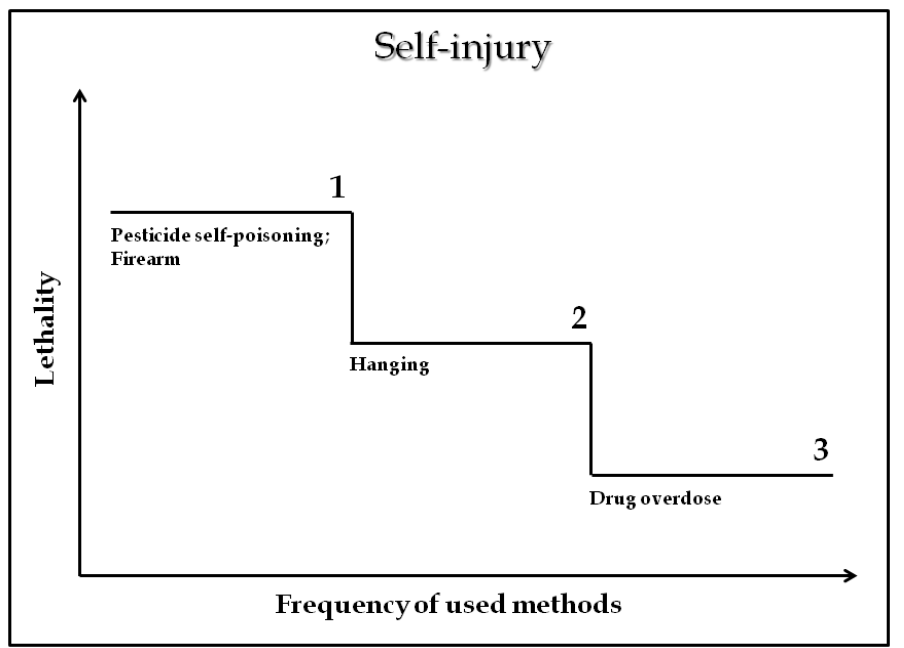

Fig. 1. Most commonly used methods of self-injury worldwide: lethality and frequency of use for suicide attempt. (1) Pesticide self-poisoning and firearm, (2) hanging, and (3) drug overdose. Drug overdose is the most common method of suicide attempt.

Towsend and colleagues (2001) observed that overdose with tranquillizers, sedatives, and antidepressants were more common in older patients and in cases of repeated suicide attempts. These findings are likely to be associated with the accessibility to the drugs. Firsttimers and younger patients are less likely to have access to prescribed medication, and hence turn to other readily available drugs, whereas repeaters and older patients are more likely to be receiving treatment for psychiatric disorders, and thus have access to psychotropic medication. In addition, the lack of marked variation between suicide intent 
and overdose of commonly used drugs may reflect the fact that many patients lack knowledge of the relative dangers of overdoses with these substances (Avanci, Pedrão \& Costa-Júnior, 2005; WHO, 2010). According to a study conducted by The Poison Information Centre in southern Brazil, suicide attempts were significant among unemployed men, housewives, and retired women. Ingestion of drugs with other substances was responsible for $51.5 \%$ of the suicide attempts. Approximately $51.1 \%$ of the men mixed the medicine with an alcoholic beverage, and $84.8 \%$ of the women used a combination of drugs. The most frequent pharmacological groups were tranquilizers $(25.5 \%)$, antidepressants $(17 \%)$, anticonvulsants (15\%) and non-steroidal anti-inflammatory drugs (11.9\%) (Bernardes, Turini \& Matsuo, 2010).

In a systematic review of published follow-up data from observational and experimental studies in Europe, North America and Australasia, Owens, Horrocks \& House (2002) found that $16 \%$ of the patients repeated the suicide attempt, and only $2 \%$ went on to committing fatal suicide in the subsequent year. The risk of suicide following non-fatal deliberate selfharm was greater in men than in women, and the risk increased with age (Hawton, Zahl \& Weatherall, 2003 ). Relative risk of suicide in females who deliberately harm themselves repeatedly is enhanced when compared with those with a single episode of deliberate selfharm. This suggests that repetition status as a risk factor may be particularly relevant when assessing risk in females (Zahl \& Hawton, 2004).

Considering patients that commit suicide, about half of them, at some point, had contact with psychiatric services, yet only a quarter had current or recent contact (Andersen et al., 2000; Lee et al., 2008). A study conducted by Gunnell \& Frankel (1994) revealed that 20-25\% of those committing suicide had contact with a health care professional in the week before death and $40 \%$ had such contact one month before death . Bancroft \& Marsack (1977) characterized three types of suicide attempters: (a) the chronic, habitual repeater; (b) the individual who repeats several times within a short period, and (c) the "one-off" very occasional repeater.

\subsection{Worldwide characteristics of antidepressants self-poisoning}

The antidepressants used in deliberate self-poisoning change according to the substances available in each country. In England, the Netherlands, Brazil, and China tricyclic antidepressants (TCAs) are more commonly used, whereas in the United States and Australia, selective serotonin reuptake inhibitors (SSRIs) are more common (Bernardes, Turini \& Matsuo, 2010; Bosch et al., 2000; Fernandes et al., 2006; Lam, Lau \& Yan, 2010; McKenzie \& McFarland, 2007; Neeleman \& Wessely, 1997; White, Litovitz \& Clancy, 2008; Wong et al., 2010). In these countries, the rates of self-poisoning with SSRIs (particularly citalopram and fluoxetine) and venlafaxine are higher than with tricyclics, especially amongst patients with a history of self-harming and psychiatric treatment (Bergen et al., 2010; Hawton et al., 2010).

Studies carried out in the 90's suggested that some SSRIs antidepressants might selectively increase suicidality (Beasley et al., 1991; Healy, Langmaak \& Savage, 1999; Teicher, Glod \& Cole, 1990). Khan and colleagues (2003) compared SSRIs with other antidepressants and placebo, and demonstrated that there was no difference in suicide risk among the patients under treatment. This suggests that the prescription of SSRIs does not seem to be associated with higher suicide rates. Nefazodone, mirtazapine, bupropion, venlafaxine, imipramine, 
amitriptyline, maprotiline, trazodone, mianserin and dothiepin were also evaluated in this study.

Although TCAs have a low therapeutic index, the fact that they are inexpensive and can be prescribed for other pathologies (migraine and polyneuropathy), facilitates their access to suicide attempters (Hawton et al., 2010; Henry, Alexander \& Sener, 1995; White, Litovitz \& Clancy, 2008). In cases of suicide by drug overdose, TCAs have the highest fatal toxicity, followed by serotonin and noradrenalin reuptake inhibitors (SNRIs), specific serotonergic antidepressants (NaSSA) and SSRIs (Chan, Gunja \& Ryan, 2010; Hawton et al., 2010). Therefore, when prescribing antidepressants, the physician should take into consideration the risk of an overdose - especially for patients that have a high risk of suicide attempt - as well as the relative efficacy and acceptability of the drug, possible interactions with other medications and alcohol, and concurrent physical morbidity.

In an analysis of 82.802 cases of suicidal antidepressant overdose registered in the United States between 2000 and 2004, White, Litovitz \& Clancy (2008) observed the following:

1. Suicidal overdoses of the newer antidepressants types peaked in younger age groups, especially when compared to antidepressants that had been marketed for decades (SSRIs and SNRIs $x$ TCAs and monoamine oxidase inhibitors);

2. Overdose by lithium peaked in patients in their twenties, TCAs and tetracyclics in their thirties, and MAO inhibitors in their forties;

3. Fatal cases peaked at 40 to 49 years of age. This may be due to the fact that more toxic and older antidepressants are more frequently prescribed in older age groups.

\section{Tricyclic and cyclic antidepressants}

\subsection{History}

Tricyclic antidepressants were the first group of drugs used to treat depression to appear in the 60 's, being amitriptyline and imipramine the main representatives of this class of drugs (Baldessarini, 2010). In the late 40's Hafliger and Schindler synthesized a series of more than 40 iminodibenzyl derivatives for possible use as an antihistamine, sedative, analgesic and antiparkinson. One of these derivatives was imipramine, a benzazepine with a three-ring chemical structure, very similar to the chemical structure of some drugs that are used to treat schizophrenia, e.g., chlorpromazine (Baldessarini, 2010; Stahl, 2006).

Currently, TCAs are being used not only in the treatment of depression, but also in various other pathologies such as panic disorders, anxiety, obsessive-compulsive disorder, eating disorders, attention deficit hyperactivity disorder, chronic pain, migraine prophylaxis and, enuresis (bed-wetting) (Leke et al., 2004; Cunha-Jr, Barrucand \& Verçosa, 2009; Margalho et al., 2007; Liebelt, 2010).

\subsection{Acute toxicity and clinical manifestations}

The determination of TCAs' toxic dose is a challenging task because in most cases, there is concurrent ingestion of these drugs and alcohol or even other drugs, and interindividual differences in weight and pharmacokinetics. However, the main limitation found is due to the fact that, even therapeutic doses of TCAs, may cause adverse effects and signs of intoxication (Woolf et al., 2007). It is also difficult to determine the toxic dose of TCAs 
because there is a lack of appropriate studies that specifically investigate the toxic threshold for these drugs, and correlate dose and effect. Data in the literature report that the ingestion of $10-20 \mathrm{mg} / \mathrm{kg}$ is considered moderate to severe exposure and cardiovascular symptom may appear (Woolf et al., 2007).

The clinical signs and symptoms that can occur in acute TCAs intoxications are often complex. A short stage of excitement and agitation is common, sometimes with myoclonus, tonic-clonic seizures or dystonia, followed by the rapid development of coma, usually with respiratory depression, hypoxia, depressed reflexes, and hypotension. Some authors report that scores less than 8 for Glasgow Coma Scale may indicate serious complications (Baldessarini, 2010; Bateman, 2005).

The toxicity of TCAs is mainly anticholinergic and cardiovascular (Baldessarini, 2010; Leke et al., 2004; Woolf et al., 2007). The main clinical consequences of anticholinergic effects are dry mouth, sour or metallic taste, epigastric pain, mydriasis, constipation, delayed gastric emptying and slow bowel movements, tachycardia, blurred vision, urinary retention, weakness, and fatigue. Although excessive sweating is a common complaint, the mechanism is still unknown.

The clinical picture reported may be manifested in different degrees of intensity. When the central nervous system (CNS) is affected, the signs and symptoms observed are loss of consciousness, delusions, and hallucinations, increased sensitivity to sounds, dizziness, agitation, and hyperthermia. The hyperthermia that occurs as a consequence of the disturbance in the regulation of body temperature may be due to, among other causes, the central anticholinergic effects of these drugs in overdoses (Baldessarini, 2010; Leke et al., 2004; Bateman, 2005).

In cases of TCA poisoning, patients may present cardiac toxicity and hypotension, and these effects can be especially difficult to control. Arrhythmias, tachycardia, fibrillation, atrioventricular and intraventricular block, and other electrocardiographic changes can also occur. Sinus tachycardia is the most common electrocardiographic abnormality. Other changes such as prolongation of the PR, QRS and QTc intervals may also occur. Prolongation of the QRS is related to clinical manifestations such as seizures and arrhythmias, and when this prolongation is greater than $100 \mathrm{~ms}$ it may indicate cardiac toxicity. Therefore, the electrocardiogram (ECG) can be a useful tool as a prognostic indicator in these types of intoxications (Baldessarini, 2010; Kiran et al., 2010; Thanacoody \& Thomas, 2005; Liebelt, 2010).

It is considered to be sinus tachycardia when the heart rate exceeds 100 beats per minute and this is mainly due to the inhibition of norepinephrine reuptake, or both. Sinus tachycardia can occur intermittently during the first three days after the intoxication and persist for up to seven days. In more severe cases of poisoning, tachycardia can be caused by myocardial depression, hypovolemia or hypotension (Thanacoody \& Thomas, 2005). According to these authors, in the early stages of the intoxication, blood pressure may be elevated, probably as result of the inhibition of norepinephrine reuptake. Posteriorly, blood pressure reduces to very low levels as a consequence of the hypovolemia, reduced peripheral resistance by alpha-adrenergic blockade, cardiac output and impaired myocardial contractility and catecholamine depletion that occur. The hypotension that occurs, which is independent of serum tricyclic levels and prolongation of the QRS interval, is strongly associated with the development of arrhythmias and pulmonary edema. 


\section{Algorithm for triage of tricyclic antidepressant ingestion}

\begin{tabular}{|c|c|c|c|}
\hline Is suicidal, abuse, or malicious intent suspected? & Yes & $\Longrightarrow$ & Refer to emergency department. \\
\hline \multicolumn{4}{|l|}{ No } \\
\hline $\begin{array}{l}\text { Is the home situation a concern (e.g., patient lives alone } \\
\text { or family/caregiver seems unreliable) }\end{array}$ & Yes & $\Longrightarrow$ & Refer to emergency department. \\
\hline \multicolumn{4}{|l|}{ No } \\
\hline $\begin{array}{l}\text { Is the patient symptomatic? (e.g., weak, drowsy, dizzy, } \\
\text { tremulous, palpitations) }\end{array}$ & Yes & $\Longrightarrow$ & Refer to emergency department. \\
\hline \multicolumn{4}{|l|}{ No } \\
\hline $\begin{array}{l}\text { Has more than } 6 \text { hours elapsed since the TCA ingestion } \\
\text { and the patient is still asymptomatic? }\end{array}$ & Yes & $\Rightarrow$ & Continue to follow closely at home. \\
\hline \multicolumn{4}{|l|}{ No } \\
\hline $\begin{array}{l}\text { Does the patient have significant underlying } \\
\text { cardiovascular or neurological disease, or is he/she } \\
\text { taking a cardiac depressant drug or MAO inhibitor? }\end{array}$ & Yes & $\Longrightarrow$ & $\begin{array}{l}\text { Consider referral to emergency } \\
\text { department. }\end{array}$ \\
\hline \multicolumn{4}{|l|}{ No } \\
\hline Can you estimate the maximum amount ingested? & & $\Longrightarrow$ & Refer to emergency department. \\
\hline \multicolumn{4}{|l|}{ Yes } \\
\hline \multicolumn{4}{|l|}{ Has the patient ingested a potentially toxic dose?* } \\
\hline \multicolumn{4}{|l|}{ Amitriptilina $>5 \mathrm{mg} / \mathrm{Kg}$} \\
\hline \multicolumn{4}{|l|}{ Clomipramina $>5 \mathrm{mg} / \mathrm{Kg}$} \\
\hline \multicolumn{4}{|l|}{ Desipramina $>2,5 \mathrm{mg} / \mathrm{Kg}$} \\
\hline \multicolumn{4}{|l|}{ Doxepin $>5 \mathrm{mg} / \mathrm{Kg}$} \\
\hline \multicolumn{4}{|l|}{ Imipramina $>5 \mathrm{mg} / \mathrm{Kg}$} \\
\hline \multicolumn{4}{|l|}{ Nortriptilina $>2,5 \mathrm{mg} / \mathrm{Kg}$} \\
\hline \multirow{2}{*}{$\begin{array}{l}\text { Protriptilina }>1 \mathrm{mg} / \mathrm{Kg} \\
\text { Trimipramina }>2,5 \mathrm{mg} / \mathrm{Kg}\end{array}$} & \multirow{3}{*}{\multicolumn{3}{|c|}{$\begin{array}{l}\text { *Algorithm applies only to ingested } \\
\text { TCA's, not to parenteral use or other } \\
\text { routes of exposures, and only in cases of } \\
\text { acute ingestions. }\end{array}$}} \\
\hline & & & \\
\hline No & & & \\
\hline $\begin{array}{l}\text { Observe at home. Instruct caller to call the poison cente } \\
\text { back if symptoms appear. Consider poison center } \\
\text { initiated follow-up within } 4 \text { hours of initial call. Conside } \\
\text { referral to emergency services should new symptom } \\
\text { develop. }\end{array}$ & & & \\
\hline
\end{tabular}

Fig. 2. Algorithm for triage of tricyclic antidepressants poisoning. Adapted from Woolf and colleagues, 2007. With permission from Taylor \& Francis INC Publisher (Order License Id: 2813741221934). TCA: Tryciclic antidrepressants. 
Thanacoody and Thomas (2005) also reported that cardiac toxicity may be enhanced in patients that develop metabolic acidosis, seizures, and hypotension. Acidosis contributes to the increase in the bioavailability of tricyclics. This provides a higher concentration of free fractions of these drugs, thus potentiating the action of tricyclics, especially on the sodium channels in myocardial cells. These antidepressants can change the conformation of sodium channels and slow cardiac conduction.

Increased risk of tonic-clonic seizures is considered to be one of the most serious toxic effects of tricyclics. The pathophysiology of these seizures is not fully elucidated, however they may occur due to a combination of factors such as the antidopaminergic and anticholinergic properties of TCAs, increased concentration of monoamines (particularly noradrenaline) and inhibition of sodium channels in neurons and interactions with GABA receptors.

Seizures usually occur in 4 out of 100 cases of tricyclic overdose and, as it is an early complication, it is unlikely to occur after 12 hours of the intoxication. If the seizures worsen, hyperthermia and rhabdomyolysis may occur as consequences of muscle hyperactivity and myoclonus. The onset of seizures can lead to brain damage and multiple organ failure. In cases of overdose, the incidence of seizures caused by amoxapine and dothiepin is especially high (Baldessarini, 2010; Stahl, 2006; Citak et al., 2006; Bateman, 2005; Liebelt, 2010).

The duration of signs and symptoms of poisoning vary according to the severity of the case. In prospective case series of 24 adults admitted with TCA overdose, only two patients developed transient supraventricular tachycardia 2 - 4 days after ingestion (Sedal et al, 1972). In retrospective studies, it was observed that only a small number of hospitalized patients developed symptoms such as hypotension and seizures more than 24 hours after ingestion of the drugs. In most of these cases, the clinical manifestations occurred within 24 hours of ingestion (Starkey \& Lawson, 1980; Biggs et al., 1977)

The duration of clinical monitoring of asymptomatic patients was also studied. Most authors agree that a six-hour period of observation, after presentation to a healthcare facility, is sufficient to monitor them for the development of major signs of toxicity (Callaham \& Kassel, 1985; Fasoli \& Glause, 1981).

Studies conducted by The Poison Control Centers in the United States, led to the elaboration of a protocol on the most adequate measures to be taken in cases of poisoning by TCAs. These researchers reached the consensus that decisions about referring patients to emergency services should be based on the patient's clinical status within the first six hours of the ingestion (Woolf et al., 2007). According to this protocol, asymptomatic patients with deliberate TCAs overdose that have not yet sought a health care unit, and after six hours remain asymptomatic, can be easily monitored at home

\section{Serotonin reuptake inhibitors}

\subsection{History}

The rate of SSRIs prescription has increased steadily since its introduction in the 80's (Ranchandani et al., 2000). In the U.S., SSRIs are considered first-line treatment of depressive disorders, and are as effective as TCAs and monoamine oxidase inhibitors (MAOIs). The commercial success of the SSRIs is due to their improved side-effect profile and reduced toxicity following overdoses when compared to TCAs. The relative safety in overdose of 
SSRIs is supported both by case series and studies of deaths/ number of prescriptions (Isbister et al., 2004; Stork, 2011).

Physicians use SSRIs to treat many other psychiatric disorders, e.g., panic disorder, obsessive compulsive disorder, social anxiety, post-traumatic stress disorder, body dysmorphic disorder, bulimia nervosa, somatoform disorders, pre-menstrual dysphoric disorder, and binge eating. Patients should be informed that the full clinical effect may take more than two weeks to occur (Hirsch \& Birnbaum,2011; Stork, 2011).

\subsection{Acute Toxicity and clinical manifestations}

SSRIs are considered to be less toxic than TCAs and MAOIs because they have an extended therapeutic window. The ingestion of up to 30 times its recommended daily dose produces little or no symptoms. The intake of 50 to 70 times the recommended daily dose can cause vomiting, mild depression of the CNS or tremors. Death rarely occurs, even at very high doses (greater than 150 times) or when SSRIs are ingested with ethanol or benzodiazepines (Hirsch \& Binrnaum, 2011).

The symptoms observed following SSRIs overdose are typically mild and manifest primarily as CNS depression. Seizures and cardiac electrophysiological abnormalities (generally QTc interval prolongation) can occur, and they are the most widely reported symptoms following citalopram overdose. Uncommonly, any agent of this class can lead to some clinical effects. These occur as consequences of the development of the serotonin syndrome, which manifests as autonomic instability, altered mental status, seizures, extrapyramidal syndrome including muscle rigidity, hyperthermia, and, rarely, death (Nelson et al., 2007; Stork, 2011).

SSRIs rarely lead to seizures, and are only reported in 1-2\% of the cases of SSRI poisoning. These seizures are usually short-lived and self-limited (Hirsch \& Birnbaum,2011). SSRIs are safer drugs than tricyclics since they have been related to less expansion of the QT interval and cardiotoxic side effects, (Açikalin et al., 2010).

Severe arrhythmia is unlikely to happen if the patient does not present any of the risk factors and the SSRIs are used at recommended doses. Some of the risk factors are enlargement of the QT, underlying cardiac disease, bradycardia, hypokalemia and hypomagnesemia, use of more than one drug that increases the QT interval, gender, and advanced age (Hirsch \& Birnbaum.,2011). The only important exception is citalopram, which can cause QTc prolongation. This provides a biologically plausible basis for the reports of increased morbidity and mortality associated with citalopram overdose (Isbister et al., 2004)

\section{Serotonergic Syndrome}

Serotonin syndrome may occur when there is concomitant use of serotonergic drugs or in cases of overdose. It consists of neuromuscular and autonomic changes that result from excessive stimulation of serotonin receptors (5-HT1A and 5-HT2A) in the CNS (Graudins, Sterman \& Chan, 1998). Signs of excess serotonin are tremor and diarrhea in mild cases, and delirium, neuromuscular rigidity, and hyperthermia in life-threatening cases (Boyer \& Michael, 2005; Poisindex, 2011). 
In cases of moderate serotonin syndrome vital sign abnormalities such as tachycardia, hypertension, and hyperthermia may appear. A core temperature as high as $400 \mathrm{C}$ is common in moderate intoxications. Signs and symptoms commonly observed in physical examinations are mydriasis, hyperactive bowel sounds, diaphoresis, and normal skin color. Interestingly, overactive reflexes and clonus in moderate cases may be greater in the lower limbs than in the upper limbs; patellar deep-tendon reflexes often demonstrate clonus for several seconds after a single tap of the tendon, whereas the brachioradialis reflex is only slightly increased. Patients may exhibit horizontal ocular clonus. Changes in mental status include mild agitation or hypervigilance, as well as slightly pressured speech. Patients may easily startle or adopt a peculiar head-turning behavior characterized by repetitive rotation of the head with the neck held in moderate extension (Boyer \& Michael, 2005).

In contrast, a patient with a severe case of the serotonin syndrome may present severe hypertension and tachycardia that may abruptly deteriorate into frank shock. These patients may have agitated delirium as well as muscular rigidity and hypertonicity. As motioned above, the increase in muscle tone is considerably greater in the lower limbs. In lifethreatening cases, muscle hyperactivity may produce a core temperature of more than $41.1{ }^{\circ} \mathrm{C}$. The laboratory abnormalities that are present in severe cases, occur when there is metabolic acidosis, rhabdomyolysis, seizures, and renal failure. Many of these abnormalities arise as a consequence of poorly treated hyperthermia (Boyer \& Michael, 2005).

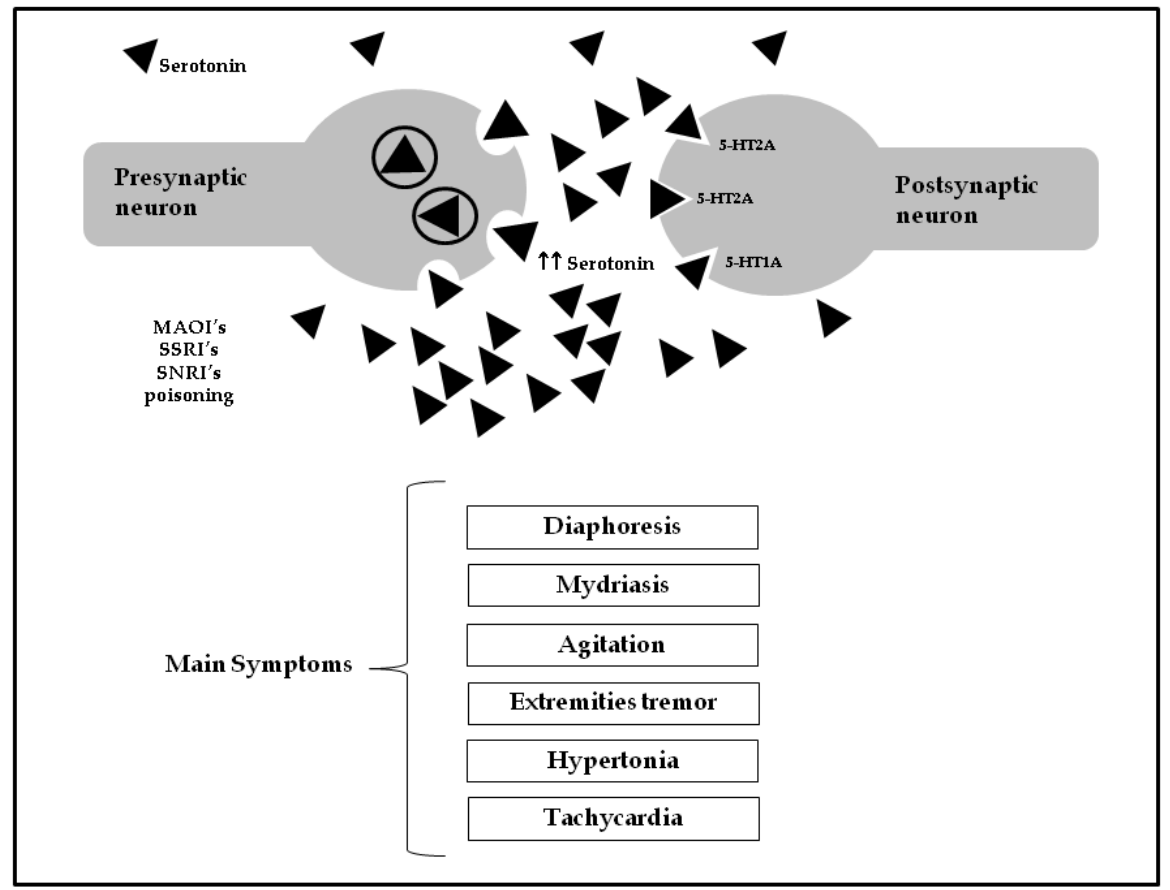

Fig. 3. Findings in moderately severe serotonergic syndrome. The excessive stimulation of serotonin receptors leads to the symptoms listed above. Neuromuscular findings should lead the clinician to consider the diagnosis of the serotonergic syndrome. 
Triage Algorithm for SSRI Poisoning in Patients of all Ages

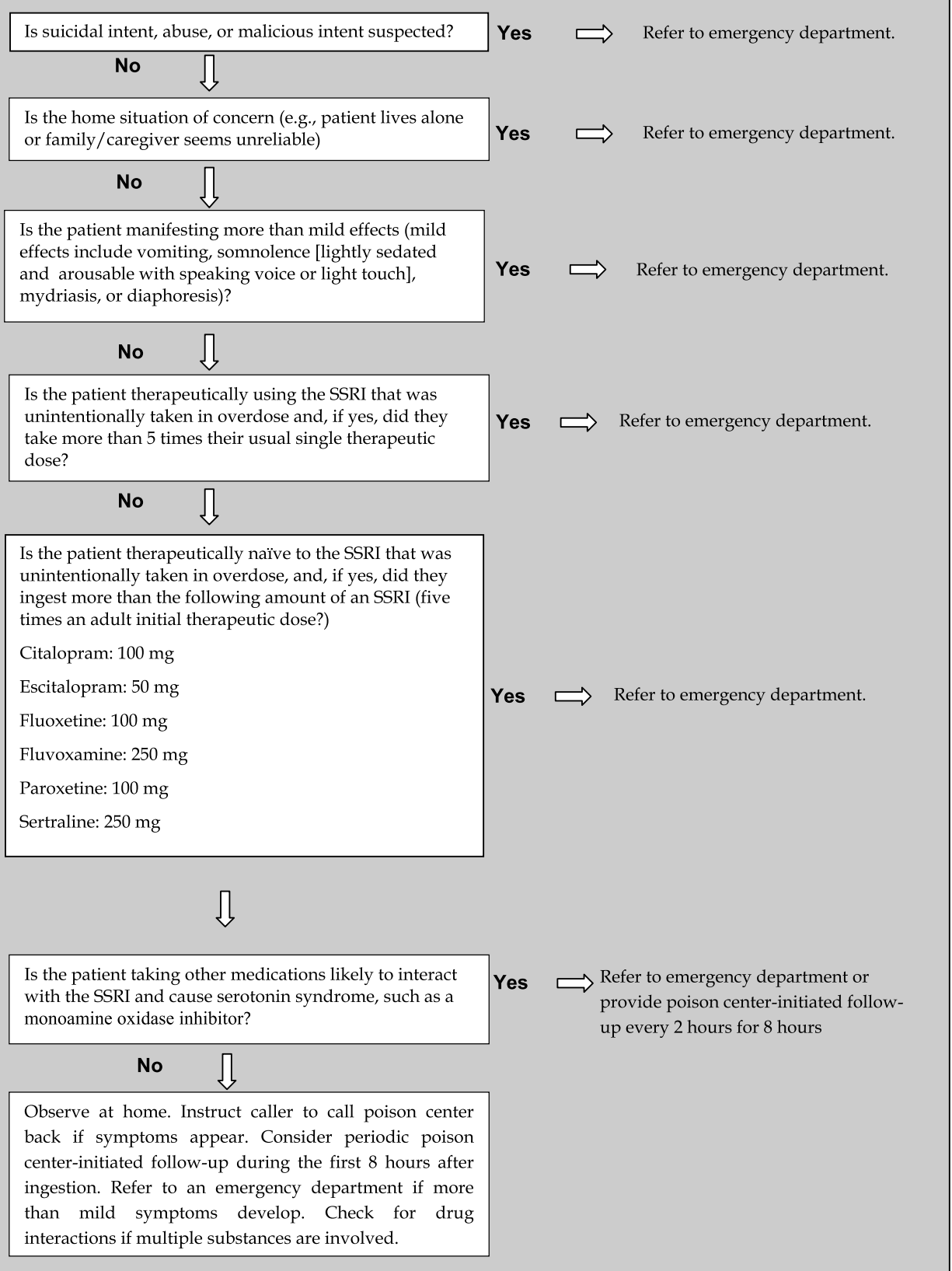

Fig. 4. Triage algorithm for SSRIs poisoning. Adapted from Nelson and colleagues, 2007. With permission from Taylor \& Francis INC Publisher (Order License Id: 2813750292586). 
According to Boyer (2011), the criteria for diagnosis of serotonin syndrome, known as Hunter criteria are:

- Spontaneous clonus

- Inducible clonus plus agitation or diaphoresis

- Ocular clonus plus agitation or diaphoresis

- Tremor and hyperreflexia

- Hypertonia

Nelson and colleagues (2007) published a triage algorithm for SSRIs poisoning based on an assessment of current scientific and clinical information, to help in clinical judgment (Figure 4).

\section{Serotonin and norepinephrine reuptake inhibitor}

\subsection{History}

Venlafaxine is the main antidepressant of the Serotonin and Norepinephrine Reuptake Inhibitor class. Low doses of this bicyclic antidepressant inhibits presynaptic reuptake of serotonin, and medium to high doses inhibits norepinephrine reuptake, therefore the term serotonin norepinephrine reuptake inhibitor (Pacher \& Kecskemeti, 2004). Venlafaxine and the structurally unrelated group of SSRIs represent a class of serotoninergic antidepressants developed and marketed, in part, on the basis of a lower risk of toxicity in overdose, when compared to TCAs and MAOIs.

SNRIs became one of the most prescribed antidepressants, especially by psychiatrists. Many symptoms of depression are caused by low dopamine levels. This class of antidepressants treats depression by stimulating dopamine in the pre-frontal cortex (Stahl, 2011). The use of venlafaxine has increased progressively since it was first introduced in 1994, especially in patients who do not respond adequately to SSRIs (Ciuna et al., 2004). In this chapter, we will focus on the most prescribed substances of the SNRI class: venlafaxine, milnacipran, duloxetine, and sibutramine. Sibutramine, however, has been used in the treatment of obesity.

Venlafaxine is a phenethylamine derivative, and was the first SNRI to be used in the U.S. This drug has different levels of serotonin reuptake inhibition when compared to norepinephrine. The inhibition of serotonin reuptake is stronger and occurs even in small doses of the drug. The inhibition of norepinephrine reuptake, on the other hand, is not as strong, so larger doses are required. Venlafaxine does not interact with any other receptor. This drug is metabolized and converted into desvenlafaxine in the liver (CYP450 2D6).

Milnacipran and duloxetine are prescribed to treat not only depression, but also algic disorders. Milnacipran was the first SNRI available in Japan and many European countries. It is more commonly used to treat algic disorders because of its singular characteristic of being a stronger inhibitor of the norepinephrine transporter than the serotonin one (Clauw et al, 2008).

SNRIs can be used to treat different clinical conditions, and may vary according to the drug, dosage, and patient's comorbidities. Some indications were already mentioned in the last section of the chapter. In general, SNRI are useful in cases of psychiatric disorders, such as 
panic disorder, social anxiety disorder, obsessive compulsive disorder, trichotillomania, attention deficit hyperactivity, and also in cases of chronic pain and fibromyalgia (Ninan, 2000). Since some antidepressants are more important to treat specific clinical conditions, physicians should analyze which antidepressant should be used to treat each case, and then decide on the best drug for the patient.

When comparing poisonings by SNRIs and SSRIs, patients who overdosed with venlafaxine were older ( $37.4 \pm 13$ vs. $28.8 \pm 10.1, P=0.001)$, had higher degree of suicidal intent, and had ingested more pills (Chan, Gunja \& Ryan, 2010). However, these observations were explained by studies that suggested that venlafaxine is prescribed to patients with higher risk of suicidal ideation.

\subsection{Acute toxicity and clinical manifestations}

SNRIs produce rapid down regulation of central beta-adrenergic receptors, and may result in a more rapid onset of toxic effects (Stork, 2011). Sodium and potassium channel blocking promotes membrane-stabilization in the heart (Charniot et al, 2010), which is rarely clinically apparent. However, QRS prolongation, QT prolongation, and ventricular tachycardia have resulted in death (Stahl, 2011). Toxicity is associated with serum concentration of venlafaxine, and chronic side-effects are alopecia, yawning, focal myositis facial flushing, and dose-related increases in blood pressure.

SNRIs are well absorbed orally and suffer no relevant influence of concurrent food ingestion, except in the case of duloxetine. All the drugs of this class are distributed through protein-biding, metabolized in the liver (P450), and excreted in the urine and feces. The elimination half-life of these drugs is 6-10 hours (except for sibutramine: 1,1 hour), and depends on existing comorbidities, such as liver disease or renal insufficiency.

Toxic doses are different among SNRIs. For instance, venlafaxine is considered toxic when doses are greater than $1500 \mathrm{mg}$ (adults) and $5.5 \mathrm{mg} / \mathrm{kg}$ (children), milnacipran, on the other hand, is toxic when doses are greater than $2800 \mathrm{mg}$.

According to Micromedex (2011), a mild to moderate intoxication can cause tremor, hyperreflexia, anxiety, and agitation. Palpitations, hypertension, tachycardia, and exacerbation of congestive heart failure have been reported in cases of ingestion of therapeutic doses and overdose. Somnolence is common in mild toxicity and delirium is more likely to happen as the toxicity increases.

Severe intoxications can lead to serotonergic syndrome (described in subitem 3.2). Cardiovascular toxicity includes PR, QRS, and QT prolongation and can occasionally culminate in ventricular tachycardia, fibrillation, and cardiac arrest. Although interval prolongations are common, ventricular dysrhythmias are rare, and are associated with large drug intake (greater than $8 \mathrm{~g}$ ). Seizures are common in patients taking over $1 \mathrm{~g}$ of the drug.

Venlafaxine can induce direct skeletal muscle toxicity and lead to severe rhabdomyolysis (Pascale et al., 2005). A case of a young adult that developed eosinophilic pneumonia after venlafaxine overdose was reported. Coma and hypotension are rare effects of severe toxicity. Sibutramine can cause thrombocytopenia and ALT, AST, and alkaline phosphatase elevations (Micromedex, 2011). Rajapakse and colleagues (2010) reported rhabdomyolysis 
and, consequently, renal failure, probably induced by a therapeutic dose of venlafaxine, in a patient with idiopathic Parkinson disease. Since this occurred in the absence of seizures, it lead the researchers to believe that this antidepressant has a certain degree of muscle toxicity. The authors also reported that the ingestion of a therapeutic dose of venlafaxine led to serotonin syndrome, which is unusual at this dose.

A case of cardiogenic shock in a middle-aged man with prior normal cardiac function was reported. Good prognosis occurs when the drug is withdrawn, the patient is treated adequately, and an ECG and echocardiography are conducted (Charniot et al, 2010).

\section{General treatment for acute antidepressants poisoning}

There is no specific antidote for acute poisoning by antidepressants, but there are ways of reducing the patient's exposure to the toxic agent. This can be done by promoting gastric decontamination and decreasing intestinal absorption. Although these procedures have been performed for many years, there are several controversies regarding their real effectiveness. The clinical manifestations of acute poising by antidepressants are complex, and depend on different factors related to the patient, such as previous diseases, and the conditions of intoxication. Therefore, it is essential that the physician understands the complexity of the situation, and that it is virtually impossible to treat all the symptoms at the same time.

\subsection{Support}

Benzodiazepines are indicated in cases of agitation, mild serotonergic effects, hyperadrenergic signs, seizures and agitation. The administration of an intravenous dose of benzodiazepine, usually diazepam, as prophylaxis in patients with potential risk for seizures is not scientifically proven. The physicians should keep in mind that the use of benzodiazepines may contribute to respiratory depression and worsen the patient's condition (Bateman, 2005; Woolf et al., 2007). Obtunded patients should be intubated and dysrhythmias, hypoventilation, and hypoperfusion should be treated with the Advanced Cardiac Life Support (ACLS). If hyperthermia persists, even after the administration of an adequate sedative, induced neuromuscular paralysis with continuous EEG monitoring should be considered. In addition, isotonic fluids should be given to replace large losses, facilitate myoglobin clearance, and promote renal clearance of the agent (Micromedex, 2011).

\subsection{Decontamination}

Gastric lavage is one of the most common gastrointestinal decontamination methods, and has been widely used for over 180 years. Recommended dose is $10 \mathrm{ml}$ of $0.9 \%$ saline per $\mathrm{kg}$ of body weight. The saline should be heated to $38^{\circ} \mathrm{C}$ in order to avoid hypothermia. If there is neurological or respiratory depression, the patient's airways should be protected before beginning the procedure. Since TCAs delay gastric emptying, this procedure can be done even after twelve hours of ingestion of the drugs (Liebelt, 2010). Gastric lavage is also recommended in massive overdoses of SNRIs, but it is only effective within 1 hour of ingestion. However, in cases of SSRI overdose, orogastric lavage usually is not recommended because it is rarely fatal (Poisindex, 201; Stork, 2011). 
Another method of decontamination often employed is the administration of actived charcoal (AC). AC absorbs toxic substances and, therefore, reduces the availability of the drug for absorption by the digestive system. Teenagers and adults are usually treated orally with 50 grams of $\mathrm{AC}$, but the conventionally accepted optimal ratio is approximately 10:1 (dose of AC/amount of drug ingested by weight) (Olson, 2010). AC may be effective in reducing the absorption of TCAs if administered shortly after the ingestion. In cases of SSRIs and SNRIs poisoning, there is greater effectiveness of AC treatment if it is given within 1-2 hours of the ingestion (Stork, 2011).

Studies analyzing the clinical course of patients receiving AC after several hours of TCAs overdose have shown a lack of efficacy in this procedure (Woolf et al., 2007). The administration of multiple doses of AC is based on the concept that the use of repeated doses may increase gastrointestinal elimination of substances present in toxic levels in the systemic circulation and have a long half life, low volume of distribution, enterogastric secretion, enteroenteric or enterohepatic circulation. Although there is no evidence of the effectiveness of multiple doses of AC, studies suggest it may increase the elimination of amitriptyline (Olson, 2010; Woolf, 2007).

In general, acute intoxications by TCAs are the most serious, for this reason alternative forms of decontamination in severe acute poisonings have been studied. Plasmapheresis is an effective method of decontamination in cases of poisoning by substances that bind to plasma proteins with high affinity, e.g., TCAs (Kolsal et al., 2009; Belen et al., 2009). Kolsal and colleagues (2009) reported a case of a two year old girl with signs and symptoms of severe intoxication by amitriptyline, with plasma concentration of $70 \mathrm{mg} / \mathrm{kg}$. The patient was in a coma and had generalized tonic clonic seizures, ventricular tachycardia and QRS interval prolongation. After conventional life support treatment, gastric lavage and AC, the patient did not have a good clinical response. However, after plasmapheresis the patient progressed well and presented no complications. Belen and colleagues (2009) also reported a case in which plasmapheresis was performed in a fifteen-year-old patient intoxicated with amitriptyline, with plasma concentration of $18 \mathrm{mg} / \mathrm{kg}$. They confirmed a reduction of $59.5 \%$ of serum level of the drug and significant improvement of electrocardiographic changes after a single session of plasmapheresis. These authors concluded that the presence of signs and symptoms such as respiratory depression, seizures, arrhythmias with QRS prolongation, or ventricular tachycardia may be considered as a criterion for choosing plasmaphereisis. This technique can be very effective in severe cases of poisoning by these drugs and when life support treatment does not contribute to a good clinical outcome. Nevertheless, it is important to conduct randomized clinical trials to analyze the efficiency of this method and substantiate these results.

\subsection{Toxic syndromes}

\subsubsection{Cardiac}

Patients with acute TCAs poisoning should undergo careful cardiac monitoring throughout their hospitalization, because of the high cardiotoxicity of these drugs. Patients with massive SSRIs and SNRIS overdose are at greater risk of cardiotoxicity, so they should have their heart monitored during 24 hours (Stahl, 2011; Stork, 2011). If the 
overdose was of citalopram or escitalopram, patients should have an ECG at least 6 hours after ingestion. If the ECG changes or shows any arrhythmia, the patient should be admitted until the normalization of the ECG. (Isbister et al., 2004). Tachycardia can be treated with fluids and sedative drugs, like benzodiazepines, and unstable ventricular dysrhythmias should be treated according to ACLS protocols. Lidocaine has been suggested as the antiarrhythmic of choice for ventricular tachycardia or ventricular fibrillation (Stork, 2011).

Sodium bicarbonate has been indicated for the treatment of the cardiovascular effects of intoxication and recommended as a preventive treatment when various clinical indicators are present, including seizures and QRS interval prolongation greater than $100 \mathrm{~ms}$. The use of sodium bicarbonate is important for the treatment of patients with TCAs poisoning. It acts as a sodium channel antagonist and corrects metabolic acidosis. The recommended dose for administration is 1 to $2 \mathrm{mEq} / \mathrm{kg}$ IV (Blackman, Brown \& Wilkes, 2001; Calkins et al., 2003). The effectiveness of sodium bicarbonate in treating cardiotoxic and neurotoxic effects has been demonstrated in experimental studies in animals and a few studies in humans. (Woolf et al. 2007; Bradberry et al. 2005; Blackman, Brown \& Wilkes, 2001, Calkins et al., 2003). According to the literature, prophylactic alkalinization in asymptomatic patients and that are not at risk of cardiovascular events is not recommended (Bradberry et al. 2005; Blackman, Brown \& Wilkes, 2001).

\subsubsection{Hyperthermia}

Benzodiazepines should be used to control agitation. During severe hyperthermia, enhance heat loss using evaporation (keep skin damp and use fans to encourage air circulation), ice water immersion or packing the patient in ice. In severe cases, the patient should be intubated and higher doses of sedatives, such as propofol, should be administrated. Occasionally, paralysis is necessary to eliminate the neuromuscular hyperactivity and rhabdomyolysis and fever (Micromedex, 2011).

\subsubsection{Serotonin syndrome}

Benzodiazepines should be given to control neuromuscular hyperactivity. Cyproheptadine has been used as a serotonin receptor antagonist, minimizing the serotonergic effects in overdose. It is only available in an oral formulation; it can be crushed and administered via nasogastric tube if the patient is unable to ingest the medication orally (Boyer \& Shannon, 2005; Boyer, 2011; Micromedex, 2011).

\subsubsection{Monitoring the patient}

In severe poisoning, patients with altered mental status, hypotension, cardiac conduction abnormalities or seizures should be monitored in an Intensive Care Unit (ICU) for five days, or longer if necessary. Complementary tests to evaluate the clinical outcome can be requested: exam to detect TCAs in the urine, ionogram (mainly sodium and potassium), complete blood cell count, aspartate aminotransferase (AST), alanine aminotransferase $(\mathrm{ALT})$, creatine phosphokinase (CK), creatine kinase-MB fraction (CK-MB), lactate dehydrogenase $(\mathrm{LDH})$, urea, creatinine and urinalysis (particularly if patient has 
rhabdomyolysis), blood glucose, arterial blood gases and chest radiograph. Determining the serum levels TCAs is not recommended since there is poor correlation between serum levels and clinical effects (Liebelt, 2010; Micromedex, 2011; Poisindex, 2011; Stork, 2011).

\section{Conclusion}

In general, antidepressants are one of the most widely used chemical agents in deliberate self-poisonings. When we talk about suicide and suicide attempt with antidepressants overdose, we are referring mainly to women in their twenties - thirties who are suicide repeaters. The antidepressants used in self-poisoning may differ in each country, however TCAs and SSRIs antidepressants are the most common. TCAs have the highest fatality rates in suicide overdose cases, followed by SNRIs and SSRIs.

Physicians treating cases of tricyclic poisoning should monitor the patients' cardiac functions, and in cases SSRIs poisoning, the physician should be aware for the development of serotonin syndrome.

The relative safety of the SSRIs when taken in overdose, when compared with TCAs and MAOIs, make them desirable drugs to be prescribed. Furthermore, SSRIs does not seem to increase suicidality, differently from what was believed two decades ago. The only important exception in toxicity is citalopram, which is associated with QTc prolongation, and this provides a biological basis for the reports of increased morbidity and mortality associated with citalopram overdose.

\section{Acknowledgments}

The authors are grateful to Miriam de Cássia Tóffolo, Poison Information Centre University Hospital - for excellent technical assistance, and Secretaria de Estado da Saúde (SESA) for the financial support.

\section{References}

Açikalin A, Satar S, Avc A, Topal M, Kuvandk G, Sebe A. QTc Intervals in Drug Poisoning Patients with Tricyclic Antidepressants and Selective Serotonin Reuptake Inhibitors. American Journal of Therapeutics, Vol.17, No. 1, (Jan-Feb 2010), pp. 30-33.

Ajdacic-Gross V, Weiss MG, Ring M, Hepp V, Bopp M, Gutzwiller F, Rössler W. Methods of suicide: international suicide patterns derived from the WHO mortality database. Bulletin of the World Health Organization, Vol. 86, No. 9, (Sep 2008), pp. 726-732.

Andersen UA, Andersen M, Rosholm JU, Gram LF. Contacts to the health care system prior to suicide: a comprehensive analysis using registers for general and psychiatric hospital admissions, contacts to general practitioners and practising specialists and drug prescriptions. Acta Psychiatrica Scandinavica, Vol.102, No.2, (Aug 2000), pp.126-134. 
Avanci RC, Pedrão J, Costa-Jr ML. Perfil do adolescente que tenta suicídio em uma unidade de emergência. Revista Brasileira de Enfermagem, Vol. 58, No. 5, (Sep-Oct 2005), pp. 535-539.

Baca-Garcia E, Diaz-Sastre C, Resa EG, Blasco H, Conesa DB, Oquendo MA, Saiz-Ruiz J, Leon J. Suicide attempts and impulsivity. European Archives of Psychiatry and Clinical Neuroscience. Vol. 255, No. 2, (Apr 2005), pp.152-156.

Baldessarini RJ, (Eds. Brunton LL, Lazo JS, Parker KL). (2010). Tratamento Farmacológico da Depressão e dos Transtornos de Ansiedade. Goodman \& Gilman: As Bases Farmacológicas da Terapêutica. McGraw-Hill, 8577260011, Porto Alegre.

Bancroft J, Marsack P. The Repetitiveness of self-poisoning and self-injury. British Journal of Psychiatry, Vol.131, (Oct 1977),:394-9.

Bateman DN. Tricyclic Antidepressant Poisoning: Central Nervous Effects and Management. Toxicology Reviews, Vol. 24, No. 3, (2005),p p.181-186.

Beasley CM, Dornseif BE, Bosomworth JC, Sayler ME, Rampey AH, Heiligenstein JH, Thompson VL, Murphy DJ, Masica DN. Fluoxetine and suicide: a meta-analysis of controlled trials of treatment for depression. British Medical Journal, Vol. 303, No. 6804, (Sep 1991), pp.685-692

Beautrais AL. Suicides and serious suicide attempts: two populations or one? Psychological Medicine, Vol. 31, No. 5, (Jul 2001), pp. 837-845.

Belen B, Akman A, Yüksel N, Dilsiz G, Yenicesu I, Olguntürk R. A Case Report of Amitriptyline Poisoning Successfully Treated With the Application of Plasma Exchange. Therapeutic Apheresis and Dialysis, Vol. 13, No. 2, (Apr 2009), p. 147-149.

Bergen H, Murphy E, Cooper J, Kapur N, Stalker C, Waters K, Hawton K.A comparative study of non-fatal self-poisoning with antidepressants relative to prescribing in three centres in England. Journal of Affective Disorders, Vol. 123, No. 1-3, (Jun 2010), pp. 95-101.

Bernardes SS, Turini CA, Matsuo T. Profile of suicide attempts using intentional overdose with medicines, treated by a poison control center in Paraná State, Brazil. Cadernos de Saúde Pública, Vol. 26, No. 7, (Jul 2010), pp. 1366-1372.

Biggs JT, Spiker DG, Petit JM, Ziegler VE. Tricyclic antidepressant overdose: incidence of symptoms. The Journal of the American Medical Association, Vol. 11. No. 2, (Jul 1977), pp. 135-138.

Blackman K, Brown SG, Wilkes GJ. Plasma alkalinization for tricyclic antidepressant toxicity: A systematic review. Emergency Medicine, Vol. 13, No. 2 (Jun 2001), p. 204210.

Bosch TM, van der Werf TS, Uges DR, Ligtenberg JJ, Fijen JW, Tulleken JE, Zijlstra JG. Antidepressants self-poisoning and ICU admissions in a university hospital in The Netherlands. Pharmacy World \& Science, Vol. 22, No. 3, ( Jun 2000), pp. 92-95.

Boyer EW, Shannon M. Current Concepts: The Serotonin Syndrome. The New England Journal of Medicine, Vol. 352, No. 1, (Mar 2005), pp. 1112-1120.

Boyer EW. Serotonin syndrome (2011). In Up to date, 2011. Available in: http://www.uptodate.com. Acessed in Oct, 2011. 
Bradberry SM, Thanacoody HK, Watt BE, Thomas SH, Vale JA. Management of the Cardiovascular Complications of Tricyclic Antidepressant Poisoning. Toxicology Reviews, Vol. 24, No. 3, (2005), p. 195-204.

Callaham M, Kassel D. Epidemiology of fatal tricyclic antidepressant ingestion: implications for management. Annals of Emmergency Medicine, (Jan 1985), Vol. 14, pp. 1-9.

Calkins T, Chan T, Clark R, Stepanski B, Vilke G. Review of prehospital sodium bicarbonate use for cyclic antidepressant overdose. Emergency Medicine Journal, Vol. 20, No. 5, (Sep 2003), pp. 483-486.

Chan AN, Gunja N, Ryan CJ. A Comparison of Venlafaxine and SSRIs in Deliberate Selfpoisoning. Journal of Medical Toxicology, Vol. 6, No. 2, (Jun 2010), pp. 116-121.

Charniot JC, Vignat N, Monsuez JJ, Kidouche R, Avramova B, Artigou JY, Albertini JP. Cardiogenic shock associated with reversible dilated cardiomyopathy during therapy with regular doses of venlafaxine. The American Journal of Emergency Medicine, Vol. 28, No. 2, (Feb 2010) pp. 256.e1-256.e5.

Citak A, Soysal DD, Uçsel R, Karaböcüoglu M, Uzel N. Seizures associated with poisoning in children: tricyclic antidepressant intoxication. Pediatrics International, Vol. 48, No. 6, (Dec 2006), p. 582-585.

Ciuna A, Andretta M, Corbari L, Levi D, Mirandola M, Sorio A, Barbui C. Are we going to increase the use of antidepressants up to that of benzodiazepines? European Journal of Clinical Pharmacoly, Vol. 60, No. 9, (Nov 2004), pp. 629- 634.

Clauw DJ, Mease P, Palmer RH, Gendreau RM, Wang Y. Milnacipran for the treatment of fibromyalgia in adults: a 15-week, multicenter, randomized, double-blind, placebocontrolled, multiple-dose clinical trial. Clin Ther. 2008; 30(11):1988-2004.

Cunha-Jr RJ, Barrucand L, Verçosa N. A Study on Electrocardiographic Changes Secondary to the Use of Tricyclic Antidepressants in Patients with Chronic Pain. Revista Brasileira de Anestesiologia, Vol. 59, No.1, (Jan-Feb 2009), p. 46-55.

Fasoli RA, Glauser FL. Cardiac arrhythmias and ECG abnormalities in tricyclic antidepressant overdose. Clinical Toxicology, Vol. 18, No. 2, (Feb 1981), pp. 155-163.

Fernandes G, Palvo F, Pinton FA, Dourado DAN, Mendes CAC. Impacto das intoxicações por antidepressivos tricíclicos comparados aos depressores do "sistema nervoso central". Arquivos de Ciências da Saúde, Vol. 13, No.3 (Jul-Set 2006), p. 61-65.

Graudins A, Sterman A, Chan B. Treatment of the Serotonin Syndrome with Cyproheptadine. The Journal of Emmergengy Medicine, Vol. 16, No. 4, (Jul-Aug. 1998), pp. 615-619).

Gunnell D, Frankel S. Prevention of suicide: aspirations and evidence. British Medical Journal, Vol. 308, No. 6938, (May 1994), pp. 1127-1233.

Gunnell D, Eddleston M. Suicide by intentional ingestion of pesticides: a continuing tragedy in developing countries International. Journal of Epidemiology, Vol. 32, No. 6, (Dec 2003), pp. 902-909. 
Guo B, Harstall C. For which strategies of suicide prevention is there evidence of effectiveness? (2004). Copenhagen, Denmark, WHO Regional Office for Europe (Health Evidence Network report;

http://www.euro.who.int/_data/assets/pdf_file/0010/74692/E83583.pdf, accessed 15 July 2011.

Hawton K, Zahl D, Weatherall R. Suicide following deliberate self-harm: long termfollowupstudy of patients who presented to a general hospital. British Journal of Psychiatry, Vol. 182, (Jun 2003), pp. 537-542.

Hawton K, Bergen H, Simkin S, Cooper J, Waters K, Gunnell D, Kapur N. Toxicity of antidepressants: rates of suicide relative to prescribing and non-fatal overdose. British Journal of Psychiatry, Vol. 196, No. 5, (May. 2010), pp. 354-358.

Healy D, Langmaak C, Savage M: Suicide in the course of the treatment of depression. Journal of Psychopharmacoly, Vol. 13, (Jan 1999), pp. 94-99

Henry JA, Alexander CA, Sener EK. Relative mortality from overdose of antidepressants. British Medical Journal, Vol. 310, No. 6974, (Jan 1995), pp. 221-224.

Hirsh M, Birnbaum RJ. Selective serotonin reuptake inhibitors (SSRIs) for treating depressed adults. Available in: http:/ / www.uptodate.com. Acessed in Oct, 2011.

Howell C, Wilson AD, Waring WS. Cardiovascular toxicity due to venlafaxine poisoning in adults: a review of 235 consecutive cases. British Journal of Clinical Pharmacology, Vol. 64, No. 2, (Aug 2007), pp. 192-197.

Isbister GK, Bowe SJ, Dawson A, Whyte IM. Relative Toxicity of Selective Serotonin Reuptak Inhibitors (SSRIs) in Overdose. Clinical Toxicology, Vol. 42, No. 3, (2004), pp. 277285.

Kessler RC, Borges G, Walters EE. Prevalence of and risk factors for lifetime suicide attempts in the national comorbidity survey. Archives of General Psychiatry, Vol. 56, No. 7, (Jul 1999), pp.617-626.

Khan A, Khan S, Kolts R, Brown WA.Suicide Rates in Clinical Trials of SSRIs, Other Antidepressants, and Placebo: Analysis of FDA Reports. The American Journal of Psychiatry, Vol. 160, No. 4, (Apr 2003), pp. 790-792.

Kiran HS, Ravikumar YS, Jayasheelan MR, Prashanth. Brugada Like Pattern in ECG with Drug Overdose. Journal of the Association of Physicians of India, Vol. 58, (Feb 2010), p. 114-115.

Kolsal E, Tekin IO, Piskin E, Aydemir C, Akyüz M, Cabuk H, Eldes N, Numanoglu V. Treatment of Severe Amitriptyline Intoxication With Plasmapheresis. Journal of Clinical Apheresis,Vol. 24, No. 1, (Jan 2009), p. 21-24.

Lam SM, Lau AC, Yan WW. Over 8 years experience on severe acute poisoning requiring intensive care in Hong Kong, China. Human \& Experimental Toxicology, Vol. 29, No. 9, (Sep 2010), pp. 757-765.

Lee HC, Lin HC, Liu TC, Lin SY. Contact of mental and nonmental health care providers prior to suicide in Taiwan: a population-based study. Canadian Journal of Psychiatry, Vol. 53, No. 6, (Jun 2008), pp. 377-383. 
Leke R, Portela LVC, Souza DO, Lara DR, Thiesen FV. Tricycles antidepressants: a review about pharmacological characteristics and therapeutic dry monitoring importance. Revista Brasileira de Toxicologia, Vol. 17, No. 2, (Dec 2004), pp. 51-54.

Liebelt EL, (Eds. Nelson LS, Lewin NA, Howland MA et al). (2011). Cyclic Antidepressants. Goldfrank's toxicologic emergencies, MCGrawHill, 978-0-07160593-9, New York.

Margalho C, Barroso M, Gallardo E, Monsanto P, Vieira DN. Massive intoxication involving unusual high concentration of amitriptyline. Human $\mathcal{E}$ Experimental Toxicology, Vol. 26, No. 8, (Aug 2007), p.667-670.

Mastrogianni O, Theodoridis G, Spagou K, Violante D, Henriques T, Pouliopoulos A, Psaroulis K, Tsoukali H, Raikos N. Determination of venlafaxine in post-mortem whole blood by HS-SPME and GC-NPD. Forensic Science International, (Jun 2011), Epub Ahed of print.

McKenzie MS, McFarland BH. Trends in antidepressant overdoses. Pharmacoepidemiology and drug safety, Vol. 16, No. 5, (May 2007), pp. 513-523.

Micromedex. Venlafaxine, 2011. In Micromedex healthcare series, 2006. Available in: http:/ / www.micromedex.com.br. Acessed in Oct, 2011.

Mines D, Hill D, Yu H, Novelli L. Prevalence of risk factors for suicide in patients prescribed venlafaxine, fluoxetine, and citalopram. Pharmacoepidemiology and Drug Safety, Vol. 14, No. 6, (Jun 2005), pp. 367-372.

Neeleman J, Wessely S. Drugs taken in fatal and non-fatal self-poisoning: a study in South London. Acta Psychiatrica Scandinavica, Vol. 95, No. 4, (Apr 1997), pp. 283-287.

Nelson LS, Erdman AR, Booze LL, Cobaugh DJ, Chyka PA, Woolf AD, Scharman EJ, Wax PM, Manoguerra AS, Christianson G, Caravati EM, Troutman WG..Selective serotonin reuptake inhibitor poisoning: an evidencebased consensus guideline for out-of-hospital management. Clinical Toxicology, Vol. 45, No. 4, (May 2007), pp. 315332.

Ninan PT. Use of venlafaxine in other psychiatric disorders. Depression and Anxiety, Vol. 12, S. 1 (2000), pp. 90-94.

Oh SH, Park NK, Jeong SH, Kim HJ, Lee CC. Deliberate self-poisoning: factors associated with recurrentself-poisoning. The American Journal of Emergency Medicine. Vol. 29, No. 8 (Oct 2011), pp. 908-912.

Olson KR. Activated Charcoal for Acute Poisoning: One Toxicologist's Journey. Journal of Medical Toxicology, Vol. 6, No. 2, (Jun 2010), pp. 190-198.

Owens D, Horrocks J, House A. Fatal and non-fatal repetition of self-harm : Systematic review. British Journal of Psychiatry, Vol. 181 (Sep 2002), pp. 181-193.

Pacher P, Kecskemeti V. Trends in the development of new antidepressants. Is there a light at the end of the tunnel? Current Medical Chemistry, Vol.11, No. 7, (Apr 2004), pp. 925-943.

Pascale P, Oddo M, Pacher P, Augsburger M, Liaudet L. Severe Rhabdomyolysis Following Venlafaxin Overdose. Therapeutic drug Monitoring, Vol. 27, No. 5, (Oct. 2004), pp. 562-565. 
Poisindex. Serotonin Syndrome. In Micromedex healthcare series, 2006. Available in: http://www.micromedex.com.br. Acessed in Oct, 2011.

Rajapakse S, Abeynaike L, Wickramarathne T. Venlafaxine-Associated Serotonin Syndrome Causing Severe Rhabdomyolysis and Acute Renal Failure in a Patient With Idiopathic Parkinson Disease. Journal of Clinical Psychopharmacoly, Vol. 30, No. 5, (Oct 2010), pp. 620-622.

Ramchandani P, Murray B, Hawton K, House A. Deliberate self poisoning with antidepressant drugs: a comparison of the relative hospital costs of cases of overdose of tricyclics with those of selective-serotonin re-uptake inhibitors. Journal of Affective Disorders, Vol.60, No.2, (Nov 2000), pp. 97-100.

Sedal L, Korman MG, Williams PO, Mushin G. Overdosage of tricyclic antidepressants. A report of two deaths and a prospective study of 24 patients. The Medical Journal of Australia, Vol. 2, No. 2, (Jul 1972), pp. 74-79.

Stahl SM.(2010). Psicofarmacologia: Bases neurocientíficas e aplicações práticas (3rd edition). Guanabara Koogan, 978-85-277-1609-3, Rio de Janeiro.

Starkey IR, Lawson AA. Poisoning with tricyclic and related antidepressants-a ten-year review. The Quartely Journal of Medicine, Vol. 49, No. 193, (1980), pp. 33-49.

Stork CM, (Eds. Nelson LS, Lewin NA, Howland MA et al). (2011). Serotonin reuptake inhibitors and atypical antidrepressants. Goldfrank's toxicologic emergencies, MCGrawHill, 978-0-07-160593-9, New York.

Thanacoody HK, Thomas SH. Tricyclic Antidepressant Poisoning: Cardiovascular Toxicity. Toxicology Reviews, Vol. 24, No. 3, (2005), p. 205-214.

Teicher $\mathrm{MH}$, Glod C, Cole JO: Emergence of intense suicidal preoccupation during fluoxetine treatment. The American Journal of Psychiatry,Vol. 147, No.2, (Feb 1990), pp. 207-210.

Townsend E, Hawton K, Harriss L, Bale E, Bond A. Substances used in deliberate selfpoisoning 1985-1997: trends and associations with age, gender, repetition and suicide intent. Social Psychiatry and Psychiatric Epidemiology, Vol. 36, No. 5 (May 2001), pp. 228-234.

Welch SS. A review of the literature on the epidemiology of parasuicide in the general population. Psychiatric Services, Vol. 52, No. 3, (March 2001), pp. 368-375.

White NC, Litovitz T, Clancy C. Suicidal antidepressant overdoses: A comparative analysis by antidepressant type. Journal of Medical Toxicology, Vol. 4. No. 4, (Dec 2008), pp. 238-250.

Wyder M, De Leo D. Behind impulsive suicide attempts: Indications from a community study. Journal of Affective Disorders. Vol. 104, No. 1-3, (Dec 2007), pp. 167-173.

Woolf AD, Erdman AR, Nelson LS, Caravati EM, Cobaugh DJ, Booze LL, Wax PM, Manoguerra AS, Scharman EJ, Olson KR, Chyka PA, Christianson G, Troutman WG. Tricyclic antidepressant poisoning: an evidence-based consensus guideline for out-of-hospital management. Clinical Toxicology, Vol. 45, No. 3, (Mar 2007), pp. 203-233.

Wong A, Taylor DMD, Ashby K, Robinson J. Changing epidemiology of intentional antidepressant drug overdose in Victoria, Australia. Australian and New Zealand Journal of Psychiatry, Vol. 44, No. 8, (Aug 2010), pp. 759-764. 
World Health Organization - Western Pacific Region. Towards evidence-based suicide prevention programmes (2010). World Health Organization [WHO], ISBN 9789929061463, Geneva, Switzerland.

Zahl DL, Hawton K. Repetition of deliberate self-harmand subsequent suicide risk: longtermfollow-up study of 11583. British Journal of Psychiatry, Vol. 181, (Sep 2002), pp. 181-193. 


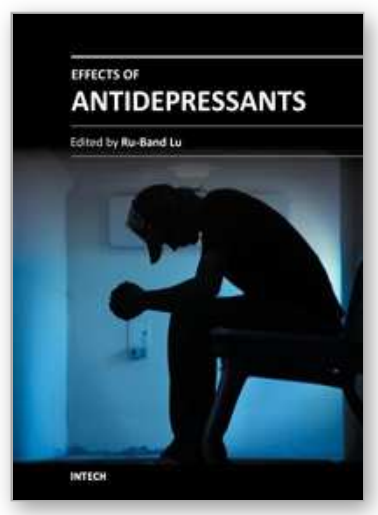

\author{
Effects of Antidepressants \\ Edited by Dr. Ru-Band Lu
}

ISBN 978-953-51-0663-0

Hard cover, 194 pages

Publisher InTech

Published online 29, June, 2012

Published in print edition June, 2012

Over the last fifty years, many studies of psychiatric medication have been carried out on the basis of psychopharmacology. At the beginning, researchers and clinicians found the unexpected effectiveness of some medications with therapeutic effects in anti-mood without knowing the reason. Next, researchers and clinicians started to explore the mechanism of neurotransmitters and started to gain an understanding of how mental illness can be. Antidepressants are one of the most investigated medications. Having greater knowledge of psychopharmacology could help us to gain more understanding of treatments. In total ten chapters on various aspects of antidepressants were integrated into this book to help beginners interested in this field to understand depression.

\title{
How to reference
}

In order to correctly reference this scholarly work, feel free to copy and paste the following:

Sara Santos Bernardes, Danielle Ruiz Miyazawa, Rodrigo Felipe Gongora e Silva, Danielle Camelo Cardoso, Estefânia Gastaldello Moreira2 and Conceição Aparecida Turini (2012). Antidepressants Self-Poisoning in Suicide and Suicide Attempt: Acute Toxicity and Treatment, Effects of Antidepressants, Dr. Ru-Band Lu (Ed.), ISBN: 978-953-51-0663-0, InTech, Available from: http://www.intechopen.com/books/effects-ofantidepressants/antidepressants-self-poisoning-in-suicide-and-suicide-attempt-acute-toxicity-and-treatment

\section{INTECH}

open science | open minds

\author{
InTech Europe \\ University Campus STeP Ri \\ Slavka Krautzeka 83/A \\ 51000 Rijeka, Croatia \\ Phone: +385 (51) 770447 \\ Fax: +385 (51) 686166 \\ www.intechopen.com
}

\author{
InTech China \\ Unit 405, Office Block, Hotel Equatorial Shanghai \\ No.65, Yan An Road (West), Shanghai, 200040, China \\ 中国上海市延安西路65号上海国际贵都大饭店办公楼 405 单元 \\ Phone: +86-21-62489820 \\ Fax: +86-21-62489821
}


(C) 2012 The Author(s). Licensee IntechOpen. This is an open access article distributed under the terms of the Creative Commons Attribution 3.0 License, which permits unrestricted use, distribution, and reproduction in any medium, provided the original work is properly cited. 